\title{
OPTIMALISASI PENDISTRIBUSIAN PUPUK DI WILAYAH SULAWESI TENGAH MELALUI MODEL TRANSSHIPMENTDENGAN MENGGUNAKAN METODE VOGEL APPROXIMATION
}

\author{
M. Safir ${ }^{1}$, S. Musdalifah², D. Lusiyanti ${ }^{3}$ \\ 1,2,3Program Studi Matematika Jurusan Matematika \\ Fakultas Matematika dan IImu Pengetahuan Alam Universitas Tadulako \\ Jalan Soekarno-Hatta Km. 9 Palu 94118, Indonesia \\ safirmuhammad10@gmail.com, selvymusdalifah@yahoo.com, desylusiyanti@gmail.com
}

\begin{abstract}
Transshipment problem is a transportation problem that allow for delivering of goods in an indirect way, where goods from a source can be transited to other sources before reaching the final destination. In this study, we use the WINQSB and POM_QM for windows program to overcome the transshipment problem. In this research, used transshipment model for modelingdistribution process and used vogel's approximation method for optimized the distribution cost. Based on the analysis and discussion found that the cost of fertilizers distribution after using vogel's approximation method is $R p .508,289,000$ compared with the real distribution cost before using vogel's approximation method is $R p .518,239,000$. It means there is difference between of distribution cost by using vogel's approximation method and the real distribution cost is $R p .9,950,000$. The result in this research showing that the transportation cost of distribution fertilizer in Central Sulawesi can be minimum using vogel approximation method and modified distribution method (MODI) for optimum test.
\end{abstract}

Keywords $\quad$ : Distribution Cost, POM-QM for windows Application, Transshipment, WinQSB Application.

\begin{abstract}
ABSTRAK
Masalah transshipment adalah masalah transportasi yang memungkinkan dilakukannya pengiriman barang dengan cara tidak langsung, di mana barang dari suatu sumber dapat berada pada sumber lain sebelum mencapai tujuan akhir. Pada penelitian ini, digunakan program WINQSB dan POM-QM for windowsdalam membantu penyelesaian masalah transshipment. Penelitian ini menggunakan model transshipment untuk memodelkan proses pendistribusiannya dan menggunakan metode Vogel' Approximationuntuk mengoptimalkan biaya pendistribusian. Berdasarkan hasil penelitian diperoleh bahwa biaya pendistribusian pupuk setelah menggunakan metode Vogel's approximation adalah sebesarRp.508,289,000dibandingkan dengan biaya transportasi awal sebelum menggunakan metode Vogel's approximation sebesarRp.518,239,000. Ini berarti terdapat selisih Rp.9,950,000antara biaya pendistribusian yang menggunakan metode Vogel's Approximationdengan biaya pendistribusian yang dilakukan. Hasil penelitian ini menunjukkan bahwa biaya transportasi pada pendistribusian pupuk di wilayah Sulawesi Tengah dapat diminimumkan menggunakan metode Vogel Approximation dan metode MODI untuk uji optimalitasnya.
\end{abstract}

Kata kunci

: Aplikasi POM-QM for windows, Aplikasi WinQSB, Biaya pendistribusian, Transshipment. 


\section{PENDAHULAN}

\subsection{LatarBelakang}

Dalam bidang pertanian pupuk merupakan salah satu hal yang paling berpengaruh terhadap hasil panen, maka tidak heran pupuk menjadi destinasi utama bagi para petani guna mendapatkan hasil panen yang melimpah dan berkualitas. Hal tersebut membuat pemerintah mencanangkan pemberian ketersediaan pupuk bersubsidi untuk para petani. Pupuk bersubsidi tersebut mereka dapatkan dari gudang penyedia pupuk yang ada didaerah tersebut. Di sisi lain ketersedian pupuk di gudang harus sesuai dengan jumlah kebutuhan petani agar tidak terjadi penimbunan atau pun kekurangan akan ketersediaan pupuk tersebut.

Beberapa perusahaan yang berwenang dalam pendistribusian pupuk bersubsidi di wilayah Sulawesi Tengah mempunyai daerah pendistribusian yang luas. Sehingga perusahaan tersebut harus mendistribusikan barang melalui pengecer ke petani dengan baik dan tepat waktu. Adapun, kendala yang sering dihadapi adalah pendistribusian yang kurang efisien, sedangkan pihak perusahaan menginginkan total biaya pengiriman minimum, sehingga diperlukan pemilihan sarana dan sistem transportasi yang paling efisien agar sesuai dengan apa yang diinginkan oleh perusahaan tersebut.

Masalah di atas dapat dibentuk menjadi model transportasi. Model transportasi adalah suatu metode yang mengoptimalkan jumlah ketersediaan dari sumber terhadap jumlah kebutuhan dalam proses distribusi.

Salah satu metode untuk menyelesaikan masalah transportasi adalah dengan menggunakan model transshipment. Model transshipment merupakan suatu masalah transportasi dimana sebagian atau seluruh barang yang diangkut dari sumber tidak langsung dikirim ke tempat tujuan tetapi melalui tempat transit. Dengan demikian tujuan utama masalah transshipment adalah untuk menentukan jumlah barang yang akan dikirim dari suatu sumber ke tempat tujuan akhir meskipun melalui tempat transit dengan ketentuan kebutuhan pada tempat tujuan akhir bisa terpenuhi, dengan total biaya distribusi yang seminimum mungkin (Sitanggang, 2010).

Masalah pada perusahaan tersebut dipandang sebagai masalah transshipment karena untuk mengirim pupuk dari tempat produksi ke petani tidak dapat dilakukan secara langsung. Pupuk yang dikirim harus melewati dua atau lebih cara pengangkutan di tempat persinggahan yang merupakan titik-titik transshipment. 
Berdasarkan uraian diatas maka penulis tertarik untuk melakukan penelitian dengan mengangkat judul "Optimalisasi Model Transshipment Pada Pendistribusian Pupuk Di Wilayah Sulawesi Tengah".

\subsection{RumusanMasalah}

Adapun rumusan masalah berdasarkan latar belakang yang telah diuraikan diatas adalah bagaimana meminimumkan biaya transportasi pada pendistribusian pupuk di wilayah Sulawesi Tengah menggunakan metode voge/ approximation.

\subsection{Tujuan Penelitian}

Tujuan yang ingin dicapai pada penelitian ini adalah meminimumkan biaya transportasi pada pendistribusian pupuk di wilayah Sulawesi Tengah menggunakan metode Vogel Approximation.

\subsection{Batasan Masalah}

Adapun batasan masalah pada penetian ini yaitu :

1. Pupuk yang didistribusikan hanya pupuk yang bersubsidi.

2. Pada penelitian ini biaya penyimpanan tidak diperhitungkan.

\section{METODE PENELITIAN}

Adapun prosedur penelitian ini adalah sebagai berikut :

1. Mulai penelitian.

2. Pengumpulan data.

3. Pembuatan tabel model transshipment.

Model transshipment merupakan perluasan dari bentuk transportasi umum, dengan kata lain bahwa model transshipment adalah model transportasi transisi atau model transportasi yang termodifikasi (Taha, 1997).

4. Mengubah model transshipment ke model transportasi umum.

Perubahan model transshipment ke model transportasi umum dilakukan agar, pengerjaan solusi layak basis dapat dilakukan. Karena pada pengerjaan solusi layak basis hanya bisa dilakukan pada model transportasi umum.

5. Menentukan variabel layak basis menggunakan metode vogel approximation.

Penentuan variabel layak basis dapat dilakukan dengan menggunakan metode vogel approximation. Pada penentuan variable layak basis ini, hasil yang diperoleh adalah jumlah alokasi pupuk ke setiap tujuan atau pengecer dari sumber atau pabrik. 
6. Uji optimalitas mengunakan metode Modified Distribution (MODI).

Setelah penentuan solusi layak basis langkah selanjutnya adalah uji optimalitas. Pada uji optimalitas ini, menggunakan metode modified distribution (MODI). Karena solusi layak basis dikatakan optimal jika dan hanya jika $\left(c_{i j}-x_{i}-\right.$ $\left.x_{j}\right) \geq 0$. Hal ini akan terlihat bahwa tidak akan ada lagi penurunan biaya jika jumlah alokasi pupuk ditambah atau dikurangkan.

7. Menentukan solusi optimal.

8. Menyimpulkan hasil penelitian.

9. Selesai.

\section{HASIL DAN PEMBAHASAN}

\subsection{Hasil}

\subsubsection{Pengumpulan Data}

Data yang diperlukan dalam penelitian ini yaitu data kebutuhan pupuk pada pengecer dan biaya transportasi pendistribusian pupuk. Pada penelitian ini data yang didapatkan berasal dari Dinas Pertanian Provinsi Sulawesi Tengah yang mana terdapat pada laporan penyaluran pupuk bulan maret 2016 dari dua produsen pupuk yaitu PT. Petrokimia Gresik dan PT. Pupuk Kaltim. Pada pendistribusian pupuk, pupuk tidak langsung dikirim ke pengecer melainkan melalui distributor dan setelah itu di distribusikan ke para pengecer. Lima distributor tersebut adalah PT. Pertani, PT. GCS, PT. Perusahaan Perdagangan Indonesia, UD. Prima Tani dan CV. Buana Prima. Pendistribusian pupuk akan dilakukan apabila para pengecer memberikan Rencana Definitif Kebutuhan Kelompok (RDKK) pada distributor kemudian ditindak lanjuti dengan mengeluarkan pupuk dari gudang penyimpanan sesuai dengan jumlah kebutuhan pupuk yang tercatat pada RDKK tersebut. Data kebutuhan pupuk pada pengecer dapat dilihat pada tabel berikut :

Tabel 1 : Kebutuhan Pupuk pada Pengecer

\begin{tabular}{|c|l|c|}
\hline No & \multicolumn{1}{|c|}{$\begin{array}{c}\text { Nama } \\
\text { Pengecer }\end{array}$} & Jumlah Kebutuhan \\
\hline 1 & Toko melati & 20 Ton \\
\hline 2 & KOP Bina Tani Mandiri & 30 Ton \\
\hline 3 & Kios Suryani & 32 Ton \\
\hline 4 & Kios Herman & 20 Ton \\
\hline 5 & Kios Eka & 189 Ton \\
\hline
\end{tabular}




\begin{tabular}{|c|l|c|}
\hline 6 & Toko Sinar Tani & 698 Ton \\
\hline 7 & Toko Sahabat Tani & 50 Ton \\
\hline 8 & Toko Cendana Tani & 58 Ton \\
\hline 9 & UD. Putra Tani & 60 Ton \\
\hline 10 & Dua Putra Jaya & 10 Ton \\
\hline 11 & Toko Semoga Indah & . \\
\hline
\end{tabular}

Sumber : : Dinas Pertanian Provinsi Sulawesi Tengah tahun 2016

Adapun biaya transportasi pendistribusian pupuk dari distributor menuju masing-masing pengecer dapat dilihat pada tabel berikut :

Tabel 2 Data biaya transportasi menurut wilayah kerja

\begin{tabular}{|c|c|c|c|c|c|c|}
\hline Kabupaten & Pengecer & PT. GCS & $\begin{array}{c}\text { PT. } \\
\text { Pertani }\end{array}$ & $\begin{array}{c}\text { CV. } \\
\text { Buana } \\
\text { Prima }\end{array}$ & $\begin{array}{l}\text { UD. } \\
\text { Prima } \\
\text { Tani }\end{array}$ & PT. PPI \\
\hline \multirow[b]{2}{*}{ Donggala } & Toko Melati & 220000 & 0 & 100000 & 0 & 100000 \\
\hline & $\begin{array}{l}\text { KOP Bina Tani } \\
\text { Mandiri }\end{array}$ & 220000 & 0 & 100000 & 0 & 100000 \\
\hline \multirow{2}{*}{ Sigi } & Kios Suryani & 40000 & 90000 & 0 & 0 & 90000 \\
\hline & Kios Herman & 40000 & 90000 & 0 & 0 & 90000 \\
\hline \multirow{2}{*}{ Parimo } & Kios Eka & 180000 & 0 & 50000 & 0 & 50000 \\
\hline & Toko Sinar Tani & 180000 & 0 & 50000 & 0 & 50000 \\
\hline \multirow{2}{*}{ Poso } & Toko Sahabat Tani & 200000 & 70000 & 0 & 70000 & 70000 \\
\hline & Toko Cendana Tani & 200000 & 70000 & 0 & 70000 & 70000 \\
\hline \multirow{2}{*}{ Morowali } & UD. Putra Tani & 0 & 0 & 70000 & 70000 & 0 \\
\hline & Dua Putra Jaya & 0 & 0 & 70000 & 70000 & 0 \\
\hline Toli-toli & $\begin{array}{l}\text { Toko Semoga } \\
\text { Indah }\end{array}$ & 0 & 70000 & 0 & 0 & 70000 \\
\hline
\end{tabular}

Sumber $\quad$ :PT. Pupuk Kaltim dan PT. GCS Cabang Palu 2016

Adapun biaya transportasi untuk pendistribusian pupuk dari kedua produsen pupuk menuju sebelas pengecer di beberapa kabupaten pada bulan maret 2016 adalah sebesar $R p .518,239,000$. Hal ini dapat dilihat dalam tabel alokasi pendistribusian pupuk berikut : 
Tabel 3 Jumlah alokasi pupuk dari pabrik ke distributor

\begin{tabular}{|l|r|r|r|r|r|r|}
\hline & $x_{3}$ & $x_{4}$ & $x_{5}$ & $x_{6}$ & $x_{7}$ & \multicolumn{1}{l|}{ Total } \\
\hline$x_{1}$ & - & - & 118 & - & 704 & 822 \\
\hline$x_{2}$ & 65 & - & 290 & 100 & - & 455 \\
\hline \multicolumn{7}{|c|}{ Total } \\
\hline
\end{tabular}

Tabel 4 Jumlah alokasi pupuk dari distributor ke pengecer

\begin{tabular}{|c|c|c|c|c|c|c|c|c|c|c|c|c|}
\hline & $x_{8}$ & $x_{9}$ & $x_{10}$ & $x_{11}$ & $x_{12}$ & $x_{13}$ & $x_{14}$ & $x_{15}$ & $x_{16}$ & $x_{17}$ & $x_{18}$ & Total \\
\hline$x_{3}$ & 20 & - & 5 & - & - & - & 40 & - & - & - & - & 65 \\
\hline$x_{4}$ & - & - & - & - & - & - & - & - & - & - & - & 0 \\
\hline$x_{5}$ & - & 30 & - & - & - & 260 & - & - & 58 & 60 & - & 408 \\
\hline$x_{6}$ & - & - & - & - & - & - & - & 100 & - & - & - & 100 \\
\hline$x_{7}$ & - & - & 27 & 20 & 189 & 438 & 10 & 10 & - & - & 10 & 704 \\
\hline Total & 20 & 30 & 32 & 20 & 189 & 698 & 50 & 110 & 58 & 60 & 10 & 1277 \\
\hline
\end{tabular}

\subsubsection{Pengumpulan Data}

Dari data biaya distribusi tersebut kita dapat membuat formulasi program linearnya sebagai berikut : terdapat dua produsen pupuk yaitu PT. Pupuk Kaltim dan PT. Petrokimia Gresik (dimisalkan $x_{1}$ dan $x_{2}$ ) mengirimkan pupuk ke lima distributor yaitu PT. GCS, PT. Pertani, CV. Buana Prima, UD. Prima Tani dan PT. PPI (dimisalkan $x_{3}, x_{4}, x_{5}, x_{6}$ dan $x_{7}$ ). Kemudian dari distributor tadi mengirimkan pupuk ke para pengecer yang membutuhkan yaitu Toko Melati, KOP Bina Tani Mandiri, Kios Suryani, Kios Herman, Kios Eka, Toko Sinar Tani, Toko Sahabat Tani, Toko Cendana Tani, UD. Putra Tani, Dua Putra Jaya dan Toko Semoga Indah (dimisalkan $x_{8}, x_{9}, x_{10}, x_{11}, x_{12}, x_{13}, x_{14}, x_{15}, x_{16}, x_{17}$ dan $\left.x_{18}\right)$.

Dalam penelitian ini jumlah permintaan sama dengan jumlah persediaan sehingga saat mengubah kedalam tabel transportasi umum tidak perlu menambahkan variabel dummy. Selanjutnya fungsi tujuan dibangun untuk meminimumkan total biaya transportasi.

Tabel 5 Biaya transportasi per ton dari pabrik ke distributor

\begin{tabular}{|c|c|c|c|c|c|}
\hline \multirow{2}{*}{ Pabrik } & \multicolumn{5}{|c|}{ Distributor } \\
\cline { 2 - 6 } & $\boldsymbol{x}_{\mathbf{3}}$ & $\boldsymbol{x}_{\mathbf{4}}$ & $\boldsymbol{x}_{\mathbf{5}}$ & $\boldsymbol{x}_{\mathbf{6}}$ & $\boldsymbol{x}_{\mathbf{7}}$ \\
\hline $\boldsymbol{x}_{\mathbf{1}}$ & - & 254500 & 254500 & 254500 & 254500 \\
\hline $\boldsymbol{x}_{\mathbf{2}}$ & 500000 & 500000 & 500000 & 500000 & 500000 \\
\hline
\end{tabular}


Tabel 6 Biaya transportasi per ton dari distributor ke pengecer

\begin{tabular}{|c|c|c|c|c|c|c|c|c|c|c|c|}
\hline \multirow{2}{*}{ Distributor } & \multicolumn{9}{|c|}{ Pengecer } \\
\cline { 2 - 14 } & $\boldsymbol{x}_{\mathbf{8}}$ & $\boldsymbol{x}_{\mathbf{9}}$ & $\boldsymbol{x}_{\mathbf{1 0}}$ & $\boldsymbol{x}_{\mathbf{1 1}}$ & $\boldsymbol{x}_{\mathbf{1 2}}$ & $\boldsymbol{x}_{\mathbf{1 3}}$ & $\boldsymbol{x}_{\mathbf{1 4}}$ & $\boldsymbol{x}_{\mathbf{1 5}}$ & $\boldsymbol{x}_{\mathbf{1 6}}$ & $\boldsymbol{x}_{\mathbf{1 7}}$ & $\boldsymbol{x}_{\mathbf{1 8}}$ \\
\hline $\boldsymbol{x}_{\mathbf{3}}$ & 220 & 220 & 40 & 40 & 180 & 180 & 200 & 200 & - & - & - \\
\hline $\boldsymbol{x}_{\mathbf{4}}$ & - & - & 90 & 90 & - & - & 70 & 70 & - & - & 70 \\
\hline $\boldsymbol{x}_{\mathbf{5}}$ & 100 & 100 & - & - & 50 & 50 & - & - & 70 & 70 & - \\
\hline $\boldsymbol{x}_{\mathbf{6}}$ & - & - & - & - & - & - & 70 & 70 & 70 & 70 & - \\
\hline $\boldsymbol{x}_{\mathbf{7}}$ & 100 & 100 & 90 & 90 & 50 & 50 & 70 & 70 & - & - & 70 \\
\hline
\end{tabular}

Sumber : PT. Pupuk Kaltim dan PT. GCS Cabang Palu 2016

Dari data di atas bisa dibuat kedalam model matematika untuk model transshipment :

Fungsi Tujuan :

Meminimumkan :

$$
\begin{aligned}
c_{1,4} x_{1,4}+c_{1,5} x_{1,5}+ & c_{1,6} x_{1,6}+c_{1,7} x_{1,7}+c_{2,3} x_{2,3}+c_{2,4} x_{2,4}+c_{2,5} x_{2,5}+c_{2,6} x_{2,6}+c_{2,7} x_{2,7} \\
& +c_{3,8} x_{3,8}+c_{5,8} x_{5,8}+c_{7,8} x_{7,8}+c_{3,9} x_{3,9}+c_{5,9} x_{5,9}+c_{7,9} x_{7,9}+c_{3,10} x_{3,10} \\
& +c_{4,10} x_{4,10}+c_{7,10} x_{7,10}+c_{3,11} x_{3,11}+c_{4,11} x_{4,11}+c_{7,11} x_{7,11}+c_{3,12} x_{3,12} \\
& +c_{5,12} x_{5,12}+c_{7,12} x_{7,12}+c_{3,13} x_{3,13}+c_{5,13} x_{5,13}+c_{7,13} x_{7,13}+c_{3,14} x_{3,14} \\
& +c_{4,14} x_{4,14}+c_{6,14} x_{6,14}+c_{7,14} x_{7,14}+c_{3,15} x_{3,15}+c_{4,15} x_{4,15}+c_{6,15} x_{6,15} \\
& +c_{7,15} x_{7,15}+c_{5,16} x_{5,16}+c_{6,16} x_{6,16}+c_{5,17} x_{5,17}+c_{6,17} x_{6,17}+c_{4,18} x_{4,18} \\
& +c_{7,18} x_{7,18}
\end{aligned}
$$

Fungsi Kendala :

$$
\begin{gathered}
x_{1,4}+x_{1,5}+x_{1,6}+x_{1,7}-\left(x_{4,1}+x_{5,1}+x_{6,1}+x_{7,1}\right)=822 \\
x_{2,3}+x_{2,4}+x_{2,5}+x_{2,6}+x_{2,7}-\left(x_{3,2}+x_{4,2}+x_{5,2}+x_{6,2}+x_{7,2}\right)=455 \\
x_{3,2}+x_{3,8}+x_{3,9}+x_{3,10}+x_{3,11}+x_{3,12}+x_{3,13}+x_{3,14}+x_{3,15} \\
\quad-\left(x_{2,3}+x_{8,3}+x_{9,3}+x_{10,3}+x_{11,3}+x_{12,3}+x_{13,3}+x_{14,3}+x_{15,3}\right)=0 \\
x_{4,1}+x_{4,2}+x_{4,10}+x_{4,11}+x_{4,14}+x_{4,15}+x_{4,18}-\left(x_{1,4}+x_{2,4}+x_{10,4}+x_{11,4}+x_{14,4}\right. \\
\left.\quad+x_{15,4}+x_{18,4}\right)=0 \\
x_{5,1}+x_{5,2}+x_{5,8}+x_{5,9}+x_{5,12}+x_{5,13}+x_{5,16}+x_{5,17}-\left(x_{1,5}+x_{2,5}+x_{8,5}+x_{9,5}+x_{12,5}\right. \\
\left.\quad+x_{13,5}+x_{16,5}+x_{17,5}\right)=0 \\
x_{6,1}+x_{6,2}+x_{6,14}+x_{6,15}+x_{6,16}+x_{6,17}-\left(x_{1,6}+x_{2,6}+x_{14,6}+x_{15,6}+x_{16,6}+x_{17,6}\right)=0 \\
x_{7,1}+x_{7,2}+x_{7,8}+x_{7,9}+x_{7,10}+x_{7,11}+x_{7,12}+x_{7,13}+x_{7,14}+x_{7,15}+x_{7,18}-\left(x_{1,7}+x_{2,7}\right. \\
\left.\quad+x_{8,7}+x_{9,7}+x_{10,7}+x_{11,7}+x_{12,7}+x_{13,7}+x_{14,7}+x_{15,7}+x_{18,7}\right)=0 \\
-\left(x_{8,3}+x_{8,5}+x_{8,7}\right)+x_{3,8}+x_{5,8}+x_{7,8}=20 \\
-\left(x_{9,3}+x_{9,5}+x_{9,7}\right)+x_{3,9}+x_{5,9}+x_{7,9}=30 \\
-\left(x_{10,3}+x_{10,4}+x_{10,7}\right)+x_{3,10}+x_{4,10}+x_{7,10}=32 \\
-\left(x_{11,3}+x_{11,4}+x_{11,7}\right)+x_{3,11}+x_{4,11}+x_{7,11}=20 \\
-\left(x_{12,3}+x_{12,5}+x_{12,7}\right)+x_{3,12}+x_{5,12}+x_{7,12}=189 \\
-\left(x_{13,3}+x_{13,5}+x_{13,7}\right)+x_{3,13}+x_{5,13}+x_{7,13}=698 \\
-\left(x_{14,3}+x_{14,4}+x_{14,6}+x_{14,7}\right)+x_{3,14}+x_{4,14}+x_{6,14}+x_{7,14}=50 \\
-\left(x_{15,3}+x_{15,4}+x_{15,6}+x_{15,7}\right)+x_{3,15}+x_{4,15}+x_{6,15}+x_{7,15}=110 \\
-\left(x_{16,5}+x_{16,6}\right)+x_{5,16}+x_{6,16}=58 \\
-\left(x_{17,5}+x_{17,6}\right)+x_{5,17}+x_{6,17}=60
\end{gathered}
$$


$-\left(x_{18,4}+x_{18,7}\right)+x_{4,18}+x_{7,18}=10$

Ket :

$x_{i j}$ :Banyaknya ton pupuk yang dikirim dari $i$ ke $j$.

$c_{i j}$ :Biaya pengiriman per ton pupuk yang dikirim dari $i$ ke $j$.

\subsection{Penyelesaian Masalah Transshipment}

Seperti masalah transportasi, tujuan masalah transshipment adalah bagaimana mengatur pengiriman agar total biayanya seminimum mungkin. Penyelesaian dengan cara mengubah masalah transshipment menjadi masalah transportasi, dan kemudian menyelesaikan dengan algoritma transportasi. Transformasi masalah transshipment ke masalah transportasi meliputi beberapa bagian, yaitu :

1. Menyeimbangkan tabel. Telitilah apakah jumlah persediaan barang sama dengan jumlah permintaan. Jika belum sama, maka tabel harus diseimbangkan dengan menambahkan sumber/tujuan semu.

2. Tentukan titik yang merupakan titik sumber, titik tujuan dan titik perantara. Titik sumber adalah titik yang hanya bisa mengirimkan barang dan tidak bisa menerima barang. Sebaliknya, titik tujuan adalah titik yang hanya bisa menerima barang. Titik perantara adalah titik yang bisa mengirimkan dan menerima barang.

3. Tentukan jumlah persediaan dan permintaan tiap titik.

Misalkan dalam masalah transshipment mula-mula, $S_{i}$ adalah persediaan titik $i$ dan $D_{j}$ adalah permintaan titik $T=\sum_{i} S_{i}=\sum_{j} D_{j}$. Maka dalam masalah transportasinya, titik sumber memiliki persediaan sebesar $S_{i}^{\prime}=S_{i}$ dan titik tujuan memiliki kebutuhan sebesar $D_{j}^{\prime}=D_{j}$. Titik perantara sebesar $P_{i}^{\prime}=S_{i}+T$ (atau permintaan sebesar $\left.D_{j}+T\right)$.

4. Tentukan biaya pengiriman dari $S_{i}$ ke $D_{j}$ (Siang, J.J, 2011).

Setelah merubah tabel transshipment menjadi tabel transportasi umum, kita sudah bisa menentukan fungsi tujuan dan fungsi kendalanya.

Fungsi tujuan yang terbentuk memiliki dua batasan, yang menyatakan bahwa jumlah barang yang dikirimkan harus lebih kecil dari jumlah barang yang tersedia ditempat asal atau perusahaan tidak dapat mengirimkan barang lebih banyak daripada kapasitas permintaan. Kedua batasan tersebut dirumuskan :

$x_{18}+x_{19}+x_{1,10}+x_{1,12}+x_{1,13}+x_{1,14}+x_{1,15}+x_{1,16}+x_{1,17}+x_{1,18} \leq 822$

$x_{28}+x_{29}+x_{2,10}+x_{2,11}+x_{2,12}+x_{2,13}+x_{2,14}+x_{2,15}+x_{2,16}+x_{2,17}+x_{2,18}, \leq 455$

Selain kedua batasan tersebut, terdapat juga sebelas batasan yang menyatakan bahwa jumlah barang yang dikirimkan ketempat tujuan harus sama atau dapat juga lebih besar dari permintaan seperti dinyatakan dalam pertidaksamaan berikut: 


$$
\begin{aligned}
& x_{18}+x_{28} \geq 20 \\
& x_{19}+x_{29} \geq 30 \\
& x_{1,10}+x_{2,10} \geq 32 \\
& x_{1,11}+x_{2,11} \geq 20 \\
& x_{1,12}+x_{2,12} \geq 189 \\
& x_{1,13}+x_{2,13} \geq 698 \\
& x_{1,14}+x_{2,14} \geq 50 \\
& x_{1,15}+x_{2,15} \geq 110 \\
& x_{1,16}+x_{2,16} \geq 58 \\
& x_{1,17}+x_{2,17} \geq 60 \\
& x_{1,18}+x_{2,18} \geq 10 \quad i=1,2 \quad j=8,9,10,11,12,13,14,15,16,17,18 \\
& x_{i j} \geq 0, \quad
\end{aligned}
$$

Dari batasan tersebut kita peroleh fungsi tujuan model program linear masalah transportasi distribusi pupuk sebagai berikut :

Meminimumkan :

$$
\begin{aligned}
& f=c_{18} x_{18}+c_{19} x_{19}+c_{1,10} x_{1,10}+c_{1,11} x_{1,11}+c_{1,12} x_{1,12}+c_{1,13} x_{1,13}+c_{1,14} x_{1,14}+ \\
& c_{1,15} x_{1,15}+c_{1,16} x_{1,16}+c_{1,17} x_{1,17}+c_{1,18} x_{1,18}+c_{2,8} x_{2,8}+c_{2,9} x_{2,9}+c_{2,10} x_{2,10}+c_{2,11} x_{2,11} \\
&+\quad c_{2,12} x_{2,12}+c_{2,13} x_{2,13}+c_{2,14} x_{2,14}+c_{2,15} x_{2,15}+c_{2,16} x_{2,16}+c_{2,17} x_{2,17} \\
&+354500 x_{18}++c_{2,18} x_{2,18} 500 x_{19}+344500 x_{1,10}+344500 x_{1,11}+304500 x_{1,12}+304500 x_{1,13} \\
&+324500 x_{1,14}+324500 x_{1,15}+324500 x_{1,16}+324500 x_{1,17} \\
&+52450 x_{1,18}+60000 x_{2,8}+600000 x_{2,9}+540000 x_{2,10} \\
&+540000 x_{2,11}+550000 x_{2,12}+550000 x_{2,13}+570000 x_{2,14} \\
&+570000 x_{2,15}+570000 x_{2,16}+570000 x_{2,17}+570000 x_{2,18}
\end{aligned}
$$

Dari batasan tersebut menunjukkan bahwa beberapa variabel keputusan $x_{i j}$ akan bersifat bebas, sehingga penyelesaian yang kita dapat akan bervariasi. Namun kita akan melihat kembali apkah penyelesaian tersebut meminimumkan fungsi tujuan atau tidak. Jika tidak, maka kita akan merevisi kembali penyelesaian tersebut. Dalam penelitian ini, data di atas dikelola untuk mendapatkan solusi layak basis dengan menggunakan metode Vogel's Approximation.

3.2.1. Langkah -langkah Penentuan Solusi Layak Basis Menggunakan Metode Vogel's Approximation.

Langkah 1 :

Dari data yang ada, kita menentukan dua sel yang memiliki biaya transportasi terendah pada setiap baris dan kolom.

Langkah 2 :

Menghitung besarnya selisih dari kedua sel tersebut pada setiap baris dan kolom.

Langkah 3 : 
Memilih salah satu nilai $D$ yang memiliki selisih terbesar dari keseluruhan baris dan kolom. Sel tersebut menunjukkan baris dan kolom yang akan di isi sesuai dengan kapasitas atau daya tampung yang memiliki biaya transportasi minimum. Jika terdapat lebih dari satu sel yang memiliki selisih terbesar, maka pilih salah satu, dimana terdapat sel yang paling rendah. Lakukan alokasi pada sel yang mempunyai sel yang paling rendah tadi dengan ketentuan $: x_{i j}=\min \left\{S_{i}-P_{j}\right\}$.

Tabel 6 Hasil solusi layak basis Matriks Metode Vogel's Approximation

\begin{tabular}{|c|c|c|c|c|c|c|c|c|c|c|c|c|c|}
\hline & $\boldsymbol{x}_{\mathbf{8}}$ & $\boldsymbol{x}_{\mathbf{9}}$ & $\boldsymbol{x}_{\mathbf{1 0}}$ & $\boldsymbol{x}_{\mathbf{1 1}}$ & $\boldsymbol{x}_{\mathbf{1 2}}$ & $\boldsymbol{x}_{\mathbf{1 3}}$ & $\boldsymbol{x}_{\mathbf{1 4}}$ & $\boldsymbol{x}_{\mathbf{1 5}}$ & $\boldsymbol{x}_{\mathbf{1 6}}$ & $\boldsymbol{x}_{\mathbf{1 7}}$ & $\boldsymbol{x}_{\mathbf{1 8}}$ & $\boldsymbol{D}$ & $\boldsymbol{S}_{\boldsymbol{i}}$ \\
\hline $\boldsymbol{x}_{\mathbf{1}}$ & 20 & 30 & & & 189 & 583 & & & & & & & 822 \\
\hline $\boldsymbol{x}_{\mathbf{2}}$ & & & 32 & 20 & & 115 & 50 & 110 & 58 & 60 & 10 & & 455 \\
\hline $\boldsymbol{D}$ & & & & & & & & & & & & & \\
\hline $\boldsymbol{P}_{\boldsymbol{j}}$ & 20 & 30 & 32 & 20 & 189 & 698 & 50 & 110 & 58 & 60 & 10 & & 1277 \\
\hline
\end{tabular}

3.2.2. Uji Optimaslitas Menggunakan Metode Modified Distribution (MODI)

Uji keoptimalan dilakukan agar mengetahui hasil dari solusi layak basis tersebut benar-benar sudah optimal atau belum, solusi layak basis dikatakan sudah optimal jika dan hanya jika $\left(c_{i j}-x_{i}-x_{j}\right) \geq 0$ untuk setiap $(i, j)$ dimana $x_{-} i j$ adalah variabel non basis. Salah satu cara uji keopimalan adalah menggunakan metode Modified Distribution (MODI). Uji optimalitas menggunakan metode MODI dilakukan dengan cara menentukan nilai $x_{i}$ untuk setiap baris dan $x_{j}$ untuk setiap kolom, berdasarkan pada rumus berikut :

$c_{i j}=x_{i}+x_{j}$

Berdasarkan hasil perhitungan yangdidapatkan, dapat disimpulkan bahwa solusi tersebut sudah optimal, karena tidak dapat lagi dilakukan penurunan biaya, bila dilakukan pengalihan alokasi ke kotak yang kosong (Siang, J.J, 2011).

\section{KESIMPULAN}

Berdasarkan hasil di atas, biaya pendistribusian pupuk menggunakan model transshipment dapat di minimumkan menggunakan metode Vogel Approximation sebesar Rp. 508,289,000, karena ditemukan selisih biaya setelah menggunakan metode Vogel's Approximation sebesar $R p .9,950,000$. 


\section{DAFTAR PUSTAKA}

[1]. Dinas Pertanian Sulawesi Tengah. 2016. Laporan pendistribusian Pupuk Bulan Maret Tahun 2016. Palu : Seksi Pupuk dan Pestisida.

[2]. Siang, J.J. 2011. Riset Operasi Dalam Pendekatan Algoritmis. Yogyakarta : Andi.

[3]. Sitanggang, Y. 2010. Studi Mengenai Permasalahan Rute Terpendek. Universitas Sumatera Utara Press. Medan.

[4]. Taha, H.A. 1997. Riset Operasi Jilid 1.Binarupa Aksara. Tangerang. 